\section{Investigación Clínica en tiempos de COVID-19}

\section{Clinical research in COVID-19 era}

\section{Señor Editor:}

La pandemia de COVID-19 representa un enorme desafío a la sociedad, y en particular a la comunidad médica y científica en diferentes ámbitos, desde el cuidado personal, el teletrabajo combinado con la asistencia a pacientes COVID-19 y no COVID-19 y el enorme caudal de información a procesar, clasificar e integrar o no al quehacer clínico. Pero este desafío aún va más allá y nos obliga a generar evidencia que contribuya al conocimiento científico y médico en el diagnóstico, tratamiento y prevención de la enfermedad y sus complicaciones. Esta información de buena calidad y no sesgada es necesaria hoy, no cuando la pandemia haya cedido ${ }^{1}$.

Desde el inicio de la pandemia en Wuhan en diciembre de 2019, así como los casos, la información ha aumentado exponencial y desorganizadamente: modo de contagio, cuadro clínico, imágenes, respuestas a tratamientos, métodos diagnósticos, factores de riesgo y mucho más. Mucha de la información inicial ha surgido desde la experiencia en China, que con 82.784 casos generó gran parte del conocimiento en especial observacional de los primeros meses. Más recientemente ha aumentado la información y publicaciones de los países europeos y EE. UU., muchos de ellos aún más afectados que China ${ }^{2}$.

Existe muchas áreas de incertidumbre que están en el día a día de la discusión clínica y que debemos ir iluminando con conocimiento científico sólido. Por ejemplo: ¿cuál es el rol del uso de mascarillas en la prevención de la expansión de la epidemia?; ¿cuál es el riesgo/beneficio de medicamentos hipotensores inhibidores de la Enzima Convertidora de Angiotensina 2 (IECAs y ARA2)? ¿cuál es la eficacia de usar hidroxicloroquina o cloroquina?; ¿qué inmunoterapia usar en qué fase de la enfermedad? Todas estas interrogantes en medio de mucha información parcial, pseudocientífica o errónea que es rápidamente difundida por medios de comunicación y redes sociales.

Los investigadores de ciencias básicas y clínicas, salubristas, epidemiólogos, bioestadísticos, tienen el deber ético de reunir información, procesarla y comunicarla durante la pandemia a fin proponer métodos de prevención y cuidados de salud. Para esto debemos, urgentemente crear las condiciones adecuadas en varios ámbitos.

Los organismos públicos debieran proveer información oficial detallada, al día y de acceso amigable. El acopio y análisis de datos en forma instantánea contribuye a extender la plataforma en la toma de decisiones.
Los comités ético científico acreditados en el país y sus organismos reguladores debieran considerar las circunstancias de emergencia sanitaria mundial, realizando revisiones éticas aceleradas, y cuando las circunstancias descritas por las pautas ética internacionales, como son:

a) la imposibilidad de obtener el consentimiento informado;

b) el importante valor social de la investigación y

c) que solo supone riesgos mínimos para los participantes, otorgar la exención de los consentimientos informados en los estudios observacionales.

Los equipos de investigación clínica, las instituciones de salud y académicas debieran organizarse, colaborar y contar con las facilidades, en la medida de los posible, para generar en forma expedita datos clínicos y epidemiológicos a partir de estudios observacionales y participar activamente de ensayos clínicos a gran escala para probar nuevos tratamientos y vacunas para enfrentar el COVID-19.

Para los estudios que venían desarrollándose antes del inicio de la pandemia, la principal preocupación debiera orientarse a proteger a los pacientes que participan en ensayos clínicos tanto del contagio de COVID-19 como la de asegurar la continuidad de sus tratamientos y cuidados médicos.

Las autoridades sanitarias y de investigación debieran incorporar el fortalecimiento y expansión de la investigación biomédica en los planes de inversión y desarrollo en el corto, mediano y largo plazo, ya que lo que estamos viviendo hoy seguramente lo volveremos a vivir en el futuro.

Los editores de revistas médicas chilenas y divulgación científica en general debieran promover la publicación de experiencias nacionales creando las condiciones para rápida evaluación y divulgación de estas publicaciones evaluadas por pares en áreas COVID-19 específicos dentro de sus portales.

Finalmente debemos impulsar la racionalidad y cautela en las múltiples intervenciones que se proponen en protocolos clínicos, manteniendo un escepticismo saludable e incertidumbre clínica ante la falta o los bajos niveles de evidencia. En especial debemos estar alertas frente a los sesgos de disponibilidad, el anclaje y el sesgo de confirmación ${ }^{3}$.

Este es uno de esos momentos donde la capacidad y la velocidad de generación y difusión de conocimiento biomédico de calidad pueden significar para las personas la diferencia entre contagiarse o no, entre tener una enfermedad grave o una leve, entre salir del ventilador mecánico o no. También para los hospitales la diferencia entre tener o no capacidad de atender a estos y otros pacientes y para las naciones, la diferencia entre atenuar o no el profundo impacto sanitario, 
social y económico que conlleva la peor pandemia de los últimos 100 años.

María Alicia Mordojovich M.D., M.Sc. ${ }^{1}$, Gabriel Cavada Ph.D. ${ }^{1}$, Andrés Maturana, M.D., M.Sc. ${ }^{1}$, Pablo M. Lavados M.D., M.P.H. ${ }^{1}$

${ }^{1}$ Unidad de Investigación y Ensayos Clínicos, Departamento de Desarrollo Académico e Investigación, Clínica Alemana de Santiago. Santiago, Chile.

\section{Referencias}

1. Roser M, Ritchie H, Ortiz-Ospina E. Coronavirus Disease (COVID-19) - Statistics and Research. Our World Data [Internet]. 2020; Available from: https://ourworldindata. org/coronavirus [citado el 10 de abril de 2020].
2. Global research on coronavirus disease (COVID-19) [Internet]. Available from: https://www.who.int/emergencies/ diseases/novel-coronavirus-2019/global-research-on-novel-coronavirus-2019-ncov [citado el 10 de abril de 2020].

3. Zagury-Orly I, Schwartzstein RM. COVID-19 - A Reminder to Reason. N Engl J Med 2020; 0 (0): null.

Correspondencia a:

Dr. Pablo M. Lavados

Unidad de Investigación y Ensayos Clínicos, Departamento de Desarrollo Académico e Investigación y Unidad de Neurología Vascular, Servicio de Neurología, Departamento de Neurología y Psiquiatría, Clínica Alemana de Santiago, Facultad de Medicina, Clínica Alemana Universidad del Desarrollo. Santiago, Chile. Av. Manquehue Norte 1410, Piso 10. Vitacura. Santiago, Chile. pablolavados@yahoo.com 